\title{
Analysis of correlation between estradiol and fracture of femur neck
}

\author{
Mohammad Davood Sharifi (1)*, Masoud Mohebbi (2), Mahmood Farrokhfar (3)*, Roohie \\ Farzaneh (1), Hamideh Feiz Disfani (1), Amir Masoud Hashemian (1)
}

(1) Department of Emergency Medicine, Faculty of Medicine, Mashhad University of Medical Sciences, Mashhad, Iran; (2) Metabolic Syndrome Research Center, Faculty of Medicine, Mashhad University of Medical Sciences, Mashhad, Iran; (3) Department of Emergency Medicine, Emergency Medicine Specialist, Hasheminejad Hospital, Mashhad University of Medical Sciences, Mashhad, Iran *Equally first authors

This article is distributed under the terms of the Creative Commons Attribution Noncommercial License (CC BY-NC 4.0) which permits any noncommercial use, distribution, and reproduction in any medium, provided the original author $(s)$ and source are credited.

\begin{abstract}
Osteoporosis is a major public health challenge all over the world. Estrogen hormone was cited amongst other hormones to be an efficient hormone for the production and maintenance of bone density. This study was designed with the purpose of evaluating and analyzing the estradiol effect on fractures of femur neck in the Iranian society. This study evaluated men over 50 years of age suffering with mild trauma (falling off the same level height or lower) and with a fracture on their femur neck. Also, their serum level of estradiol was measured with an ELISA method. Using this procedure, the patients were assigned into groups with either normal estradiol serum level $(10 \mathrm{pg} / \mathrm{ml}$ and higher) or with lower than normal level (lower than $10 \mathrm{pg} / \mathrm{ml}$ ). A control group including 50-year-old and older men without hip fracture, or its history, was chosen to access their estradiol serum level. Data collected from these two groups were statistically compared. A total of 120 patients were evaluated (60 in the control and 60 in the test group). The mean age of patients in the control and test groups were $67.9 \pm 10.22$ and $69.5 \pm 8.84$ years, respectively $(\mathrm{p}=0.376)$. Smoker patients' percentages in the control and test groups were $35 \%$ and $31.7 \%$, respectively $(\mathrm{p}=0.699)$. On the basis of the serum estradiol level, patients' percentages with low estradiol level in control and test groups were $10 \%$ and $16.7 \%$, respectively $(\mathrm{p}=0.283)$. The only significant factor in predicting serum estradiol level was smoking. In conclusion, in this study it was observed that fractures of the femoral neck following a mild trauma were not correlated to low level of serum estradiol.
\end{abstract}

Key Words: Estradiol, fracture, neck of femur, men, osteoporosis

Eur J Transl Myol 28 (2): 215-219, 2018

Osteoporosis is a significant public health challenge that is characterized by skeletal disorder with compromised bone strength which results from the decrease in bone mineral density (BMD). ${ }^{1-3}$ The mass destruction in microstructures of bone tissue is closely observed as it might result in an increase in the risk of bone fracture. ${ }^{4,5}$ Osteoporosis is the most prevalent age related bone metabolic disorder which, subsequently, predisposes to an increased risk of fracture that, in turn, leads to disability of the individual and causes high costs to society. ${ }^{6-8}$ Hip fractures burden, actually, with $1 \%$ on total leg fractures. Factors such as race, physical activity, body composition, the amount of calcium and VitaminD intake are responsible for osteoporosis in males. ${ }^{9}$ Estrogen hormone is particularly efficacious in skeletal development, maintenance of Bone Mineral Density
(BMD) and prevention of fractures. ${ }^{10}$ In most postmenopausal women, serum estradiol level decreases and reaches about $10 \%$ of the value before menopause. Rapid decrease in BMD and progression of osteoporosis occurs in most women without any replacement. ${ }^{11,12}$ Although the influence of estradiol is more significant on women, low concentration of 17-beta-estradiol is associated with reduction of cortical thickness of long bones in aged men. ${ }^{13,14}$ Several surveys have shown that there is a direct relation in BMD between testosterone and estradiol levels. ${ }^{15-19}$ Our study is focused on the association between total serum estradiol level and fracture risk of femoral neck in patients referred to the two university hospitals of Imam Reza and Hasheminejad. 


\section{Materials and Methods}

The ethics committee of Mashhad University of Medical Sciences approved protocol of this study and a written informed consent was taken from all subjects. Men of over 50 years with fracture of femoral neck without low BMD were the sample size for this study. Considering the aims of the study, at least 120 subjects were required to perform statistical tests with the power of $80 \%$. 120 random men over 50 years admitted to Imam Reza and Hasheminejad hospitals of Mashhad were entered into the study. The sample size measurement was calculated with Number Cruncher Statistical \& Power Analysis and Sample Size (NCSS\&PASS). The subjects were classified into two groups ( 60 for the case and 60 for the control group). Serum estradiol level was measured based on the ELISA method. Based on the estradiol level, the subjects were divided into adequate $(\leq 10 \mathrm{pg} / \mathrm{ml})$ and deficient $(\geq 9 \mathrm{pg} / \mathrm{ml})$ levels. Men older than 50 years without neck of femure fracture were evaluated for the concentration of estradiol and were divided into adequate and deficient groups. This cut-off point was defined based on the levels associated with the risk for osteoporotic fracture; thus, levels above 10 are considered adequate and higher levels which are hyperestrogenemia were not separated. Patients with the previous history of femur's fracture, known pathologic problems in femur (e.g. tumors and cysts), and history of treatment with corticosteroids were excluded from the study. Data gathering consisted of the following variables: age and weight. The history of age of the two groups was defined as below 65 and over 65 years old; the weights of the groups were: below 80 and over 80 kilograms and the last groups were smoking and nosmoking. Serum estradiol level was measured based on the ELISA method. Independent sample T test was used to compare age and weight of the patients and control groups. Pearson chi-square and logistic regression were performed to evaluate the results. Multivariate regression analysis was utilized to evaluate the role of factors in predicting serum estradiol levels. Significance level was considered as P-values lower than 0.05. Statistical analysis was carried out using SPSS version 17.

\section{Results and Discussion}

Case-control study consisted of 120 individuals older than 50 years. It included 60 cases of accidental femoral fracture. 60 men older than 50 years without femoral fracture were entered into the control group. The mean age in patients and control groups was $69.5 \pm 8.84$ and $67.9 \pm 10.22$ respectively $(\mathrm{p}=0.376)$. The mean weight of the patients' and control groups was $67.7 \pm 12.49 \mathrm{Kg}$ and $68.4 \pm 11.79 \mathrm{Kg}$ respectively $(\mathrm{P}=0.776)$ (Table 1$)$. The percentage of smokers in patient and control groups was $31 \%$ and $35 \%$, respectively $(\mathrm{P}=0.699)$ (Table 2$)$. The frequency of adequate and deficient estradiol levels was compared among the patients and control groups. There was no significant difference between patients with low serum estradiol level and femur's fracture following mild trauma and patients without hip fracture or with a history of hip fracture (Table 3). According to the multivariate regression analysis, the only significant factor in predicting serum estradiol level was smoking (Table 4). This study showed that there is no significant difference between patients with low estradiol level and a fracture following mild trauma and persons without femoral fracture or a history of hip fracture. In other words, femur's fracture was not the result of low level of serum estradiol and the association of etsradiol-hip fracture is inconsistent and probably related to multifactorial causes of hip-fracture risk. Consistent with our study, several studies reported that there is no association between low estradiol and fracture risk in men. ${ }^{20-22}$ Bojenerem et al found that there was no effect of estradiol on fracture risk; and sex steroids could not predict the risk of nonvertebral fracture. ${ }^{20}$ Legrand et al showed that there was no significant difference in estradiol level between osteoporotic men and controls. Results of their study showed that estradiol levels do not correlate with bone formation or bone reabsorption markers. ${ }^{23}$ In addition, Channing et al, in a cross sectional study of US population, evaluated 1185 adult men. They did not observe any association between total estradiol (E2) and BMD in men. ${ }^{24}$ However, there were several studies that revealed the association between low serum estradiol levels and fracture risk in women, ${ }^{25-28}$ and men, ${ }^{26}$ thereby making the probable impact of sex steroids on fracture risk unclear. ${ }^{29}$ Fink et al, in a large longitudinal analysis, presented that old men with low BMD-osteoporosis in the femur neck were more likely to have estradiol deficiency. ${ }^{30}$ Szulc et al showed that the low levels of estradiol-E2 were negatively correlated with BMD in men over 50 years old. ${ }^{27}$ Fracture risk for men in the first quartile of serum estradiol-17 E2 was 50-100\% higher than men with the highest quartile of $17 \mathrm{E} 2 .^{27,31}$ In

Table 1. Age and weight characteristics of study participants

\begin{tabular}{llll}
\hline & Patients group & Control group & P value \\
\hline & Mean \pm SD & Mean \pm SD & \\
Age & $69.5 \pm 8.84$ & $67.7 \pm 10.29$ & 0.376 \\
Weight & $67.7 \pm 12.49 \mathrm{Kg}$ & $68.4 \pm 11.79 \mathrm{Kg}$ & 0.776 \\
\hline
\end{tabular}


Table 2. Simple correlation of cigarette smoking (\%) with fracture risk

\begin{tabular}{|c|c|c|c|c|}
\hline \multirow{2}{*}{$\begin{array}{l}\text { cigarette } \\
\text { smoking }\end{array}$} & \multicolumn{2}{|l|}{ Yes } & \multicolumn{2}{|l|}{ no } \\
\hline & Number & Percent & Number & Percent \\
\hline $\begin{array}{l}\text { Patient } \\
\text { group }\end{array}$ & 19 & 31.7 & 41 & 68.3 \\
\hline $\begin{array}{l}\text { Control } \\
\text { group }\end{array}$ & 21 & 35 & 39 & 65 \\
\hline Total & 40 & 33.3 & 80 & 66.7 \\
\hline
\end{tabular}

Table 3. Simple correlation of estradiol (\%) level with fracture risk

\begin{tabular}{|l|l|l|l|l|}
\hline \multirow{2}{*}{$\begin{array}{l}\text { Estradiol } \\
\text { level }\end{array}$} & $\leq 9 \mathrm{pg} / \mathrm{ml}$ & \multicolumn{2}{|c|}{$\geq 10 \mathrm{pg} / \mathrm{ml}$} \\
\cline { 2 - 5 } & Number & Percent & Number & Percent \\
\hline $\begin{array}{l}\text { Case } \\
\text { group }\end{array}$ & 6 & 10 & 54 & 90 \\
\hline $\begin{array}{l}\text { Control } \\
\text { group }\end{array}$ & 10 & 83.3 & 50 & 83.3 \\
\hline Total & 16 & 86.7 & 104 & 86.7 \\
\hline P value & $\mathrm{P}=0.263$ & \multicolumn{4}{|l}{} \\
\hline
\end{tabular}

Table 4. Association between smoking (\%) and serum estradiol level

\begin{tabular}{|l|l|l|l|l|}
\hline \multirow{2}{*}{$\begin{array}{l}\text { Estradiol } \\
\text { leve } \\
\text { Smoking }\end{array}$} & $9 \mathrm{pg} / \mathrm{ml}$ and lower & \multicolumn{2}{|l|}{$10 \mathrm{pg} / \mathrm{ml}$ and higher } \\
\cline { 2 - 5 } & Number & Percent & Number & Percent \\
\hline Yes & 9 & 22.5 & 31 & 77.5 \\
\hline No & 7 & 8.8 & 73 & 91.3 \\
\hline Total & 16 & 13.3 & 104 & 86.7 \\
\hline P value & \multicolumn{4}{|l}{} \\
\hline
\end{tabular}

addition, the influence of low estradiol level on BMD is strengthened if associated with low testosterone and high Sex Hormone Binding Globulin levels. ${ }^{27}$ In contrast with our study, BMD is a more accurate measure of bone health compared with fracture of femoral neck. ${ }^{30}$ Woo et al. claimed that the most powerful association was between total estradiol and femoral BMD, and osteoporosis was mostly observed in men with estradiol level $<18.8 \mathrm{pg} / \mathrm{ml}$. A strong relationship was observed in non-vertebral fractures (hip, radius, and arm). After adjustment for BMD, there was not any significant relationship between total estradiol and femoral fracture. ${ }^{31}$ In many of the previous studies, the correlation between sex steroids and fracture risk was attenuated after adjusting for BMD, ${ }^{32}$ and, as far as we know, estradiol as predictive signal in relation to BMD was not found in recent studies. Most studies, actually, emphasized the effect of estradiol on bone mineral density as an endpoint. ${ }^{7,20,21,29,31}$ Mellstrom et al. evaluated 2639 Swedish old men over 3.3 years and according to a multivariable regression analysis; free estradiol was independently associated with vertebral, non-vertebral and hip fracture risk. ${ }^{28}$ Until now, in most studies, the inverse correlation between estradiol level and fracture risk was revealed only below a specific cutpoint of serum estradiol. It appeared that there was a serum estradiol threshold below which fracture risk tend to increase; above this level there is no correlation between the estradiol level and fracture risk..$^{23,27,30}$ According to most study, there is a nonlinear relationship 
between total estradiol-E2 and fracture risk below dichotomous cut-off point of estradiol (12 and $16 \mathrm{pg} / \mathrm{ml}) .{ }^{29}$ To our knowledge, the minimal level of estradiol was required for osteocyte bioavailability. In addition, serum estradiol levels were higher in men compared with postmenopausal women; men being well above the minimal required level for bone health. ${ }^{32}$ There are several other explanations that supported the absence of any association between femoral fracture risk and sex steroids. Limited number of fractures and reliance on immunoassays with inadequate accuracy in low concentrations might explain our negative results. Single measurement of estradiol does not properly reflect long term exposure to estradiol deficiency. ${ }^{20}$ Furthermore, femoral fracture seems to be less related to bone fragility than vertebral fractures. ${ }^{32}$ In summary, although several studies suggested that higher fracture rates were linked to lower estradiol levels, there were few publications that do not support the hypothesis in agreement with our data. ${ }^{33}$ This study had some limitations. Our results from a retrospective study were difficult to interpret. One of the most important limitations of our study was the relatively low number of patients in our study. In addition, the subjects do not reflect the entire populations; therefore, our negative results might be due to low statistical power. Hormonal status determination by a single measurement for estradiol level could have diluted the correlation. Measurement of estradiol was not performed by gold standard methods (liquid chromatography/mass spectrophotometry); thus, we will reinforce the study with highly sensitive techniques. In addition, we did not consider co-morbidity that could affect estradiol levels. There were several confounders factors like BMI that were not evaluated. In addition, it seems that femoral neck fracture was not a good criterion for osteoporosis in contrast with BMD in other studies. ${ }^{30}$ Moreover, in the last decade, most studies evaluated the association between additional factors like serum level of biological estradiol, sex hormone binding globulin, testosterone, aromatase enzyme activity and bone mineral density. ${ }^{34}$ In general, despite several evidences that supported the positive effect of sex steroid on bone metabolism in experimental animal models, clinical studies have not confirmed their independent predictive role in bone fracture. ${ }^{34}$ In conclusion, there was no clear association between estradiol serum level and fracture risk in old men. Our analysis was not helpful to assess whether fracture risk was estradiol dependent. Other communitybased studies with larger sample sizes and standardized methods for sex steroid are required to confirm it. However, the study confirmed the value of using BMD to evaluate bone health status.

\section{List of acronyms}

NCSS\&PASS - Number Cruncher Statistical \& Power Analysis and Sample Size

BMD - Bone Mineral Density

ELISA - Enzyme-linked Immunosorbent Assay

\section{Author's contributions}

Each author contributed in equal part to the manuscript.

\section{Acknowledgments}

This study was a thesis of Dr. Mohammad Farrokhfar for the degree in Specialization in post-lauream School in emergency medicine, under the supervision of Professor Amir Masoud Hashemian and with Professor Kooroosh Ahmadi as his adviser. Funding: None.

\section{Conflict of Interest}

The authors declare no conflicts of interests.

\section{Ethical Publication Statement}

We confirm that we have read the Journal's position on issues involved in ethical publication and affirm that this report is consistent with those guidelines.

\section{Corresponding Author}

Amir Masoud Hashemian, Department of Emergency Medicine, Faculty of Medicine, Mashhad University of Medical Sciences, Mashhad, Iran.

Phone 00989124244517

Email: hashemianam@mums.ac.ir

E-mail of co-authors

Mohammad Davood Sharifi: sharifimd@mums.ac.ir Mahmood Farrokhfar: sharifimd@mums.ac.ir Masoud Mohebbi:mohebbim@mums.ac.ir Roohie Farzaneh: farzanehrh@mums.ac.ir Hamideh Feiz Disfani:feyzh@mums.ac.ir

\section{References}

1. Vandewalle S, Taes Y, Fiers T, et al. Association of sex steroids with bone maturation bone mineral density, bone geometry and body composition: a cross-sectional study in healthy male adolescents. J Clin endocririnol Metab 2014;99: E1272-82.

2. Seeman E. Estrogen, androgen, and the pathogenesis of bone fragility in women and men. Curr Osteoporos Rep 2004;2:90-96.

3. Glaser DL, Kaplan FS. Osteoporosis. Definition and clinical presentation. Spine 1976;22:12S-6S.

4. Vandenput L, Ohlsson C. Sex steroid metabolism in the regulation of bone health in men. J Steroid Biochem Mol Biol 2010;121:582-8.

5. Bjørnerem A, Emaus N, Berntsen GK, et al. Circulating sex steroids, sex hormone-binding globulin, and longitudinal changes in forearm bone mineral density in postmenopausal women and men: the Tromso study. Calcif Tissue Int 2007;81:65-72.

6. Ohlsson C, Börjesson AE, Vandenput L. Sex steroid and bone health in men. Bonekey Rep 2012 Jan 10;1:2. doi: 10.1038/bonekey.2012.3.

7. Khosla S, Melton LJ 3rd, Robb RA, et al. Relationship of volumetric BMD and structural 
parameters at different skeletal sites to sex steroid levels in men. J Bone Miner Res 2005;20:730-40.

8. Hansen LB, Vondracek SF. Prevention and treatment of non-postmenopausal osteoporosis. Am J Health Syst Pharm 2004;24:2637-54.

9. Khosla S, Melton LJ 3rd, Atkinson EJ, et al. Relationship of serum sex steroid levels and bone turnover markers with bone mineral density in men and women: a key role for bioavailable estrogen. J Clin Endocrinol Metab 1998;83:2266-74.

10. Randell A, Sambrook PN, Nguyen T, et al. Direct clinical and welfare costs of osteoporotic fractures in elderly men and women. Osteoporos Int 1995;5:427-32.

11. Garnero P, Sornay-Rendu E, Claustrat B, et al. Biochemical markers of bone turnover, endogenous hormones and the risk of fractures in postmenopausal women: the OFELY study. J Bone Miner Res 2000;15:1526-36.

12. NavehT, Silver J. Regulation of parathyroid hormone gene expression by hypocalcemia, hypercalcemia, and vitamin $\mathrm{D}$ in the rat. J Clin Invest 1990;86:1313-19.

13. Silve CM, Hradek GT, Jones AL, Arnaud CD. Parathyroid hormone receptor in intact embryonic chicken bone: characterization and cellular localization. J Cell Biol 1982;94:379-86.

14. Herrmann-Erlee MP, Heersche JN, Hekkelman JW, et al. Effects of bone in vitro of bovine parathyroid hormone and synthetic fragments representing residues 1-34, 2-34 and 3-34. Endocr Res Commun 1976;3:21-35.

15. Heath JK, Atkinson SJ, Meikle MC, Reynolds JJ. Mouse osteoblasts synthesize collagenase in response to bone resorbing agents. Biochim Biophys Acta1984 Nov 6; 802(1):151-4.

16. Simon LS1, Slovik DM, Neer RM, Krane SM. Changes in serum levels of type I and III procollagen extension peptides during infusion of human parathyroid hormone fragment (1-34). J Bone Miner Res 1988;3:241-6.

17. Wong GL, Luben RA, Cohn DV. 1,25dihydroxycholecalciferol and parathormone: effects on isolated osteoclast-like and osteoblastlike cells. Science 1977; 197:663-5.

18. Henry HL. Vitamin D hydroxylases. J Cell Biochem 1992;49:4-9.

19. Hoppe E, Bouvard B, Royer M, et al. Sex hormone binding globulin in osteoporosis. Joint bone spine 2010;77:306-12.

20. Bjørnerem A, Ahmed LA, Joakimsen RM, et al. A prospective study of sex steroids, sex hormonebinding globulin and non-vertebral fractures in women and men: the tromso study. Eur J Endocrinol 2007;157;119-25.

21. Vanderschueren D, Laurent MR, Claessens F, et al. Sex steroid actions in male bone. Endocrine Rev 2014;35:906-60.
22. Gennari L, Merlotti D, Martini G, et al. Longitudinal association between sex hormone levels, bone loss, and bone turnover in elderly men. J Clin Endocrinol Metab 2003;88:5327-33.

23. Legrand E, Hedde C, Gallois Y, et al. Osteoporosis in men: a potential role for the sex hormone binding globulin. Bone 2001;29:90-5.

24. Paller C, Shiels MS. Relationship of Sex Steroid Hormones with Bone Mineral Density (BMD) in a Nationally Representative Sample of Men. Clin Endocrinol 2009;70:26-34.

25. Barrett-Connor E, Mueller JE, von Mühlen DG, et al. Low levels of estradiol are associated with vertebral fractures in older men, but not women: the Rancho Bernardo Study. J Clin Endocrinol Metab 2000;85:219-23.

26. Cummings SR, Browner WS, Bauer D, et al. endogenous hormones and the risk of hip and vertebral fractures among older women. Obstetrical \& gynecological survey 1999;339:732-8.

27. Szulc P, Uusi-Rasi K, Claustrat B, et al. Role of sex steroids in the regulation of bone morphology in men. The MINOS study. Osteoporos Int 2004;15:909-17.

28. Mellström D, Vandenput L, Mallmin H, et al. Older men with low serum estradiol and high serum SHBG have an increased risk of fractures. J Bone Miner Res 2008;23:1552-60.

29. Chapurlat RD, Garnero P, Bréart G, et al. Serum estradiol and sex hormone-binding globulin and the risk of hip fracture in elderly women: the EPIDOS study. J Bone Miner Res 2000;15:1835-41.

30. Fink HA, Ewing SK, Ensrud KE, et al. Association of testosterone and estradiol deficiency with osteoporosis and rapid bone loss in older men. J Clin Endocrinol Metab 2006;91: 3908-15.

31. Woo J, Kwok T, Leung JC, et al. Sex steroids and bone health in older Chinese men. Osteoporos Int 2012;23:1553-62.

32. Hermein W. Goderie P. Endogenous Sex Hormones, Sex Hormone-Binding. Globulin, and the Risk of Incident Vertebral Fractures in Elderly Men and Women: The Rotterdam Study. J Clin Endocrinol Metab 2004;89:3261-9.

33. LeBlanc E, Carrie M. The Effects of Serum Testosterone, Estradiol, and Sex Hormone Binding Globulin on fracture risk in old men. J Clin Endocrinol Metab 2009;94:3337-46.

34. Austin H, Drews C, Partridge EE. A case-control study of endometrial cancer in relation to cigarette smoking, serum estrogen levels, and alcohol use. Am J Obstet Gynecol 1993;169:1086-91.

Submission: $25 / 02 / 18$

Revisions received: 29/04/18

Acceptance: 29/04/18 
Estradiol and fracture of femur neck

Eur J Transl Myol 28 (2): 215-219, 2018 